\title{
The development of squamous cell carcinoma in a patient after kidney transplantation: a case report
}

\author{
Henryk Witmanowski ${ }^{1,2}$, Małgorzata Lewandowska ${ }^{3}$, Paweł Szychta ${ }^{4}$, Stanisław Sporny ${ }^{5}$, Jan Rykała ${ }^{4}$ \\ 1Department of Plastic, Reconstructive and Aesthetic Surgery, Collegium Medicum, Nicolaus Copernicus University, Bydgoszcz, Poland \\ Head: Prof. Henryk Witmanowski MD, PhD \\ 2Department of Physiology, Poznan University of Medical Sciences, Poland \\ Head: Prof. Hanna Krauss MD, PhD \\ ${ }^{3}$ Department of Pathology of the Age of Development, Medical University of Lodz, Poland \\ Head: Prof. Józef Kobos MD, PhD \\ ${ }^{4}$ Department of Plastic, Reconstructive and Aesthetic Surgery, Medical University of Lodz, Poland \\ Head: Prof. Bogusław Antoszewski MD, PhD \\ ${ }^{5}$ Department of Dental Pathology, Medical University of Lodz, Poland \\ Head: Prof. Stanisław Sporny MD, PhD
}

Postep Derm Alergol 2013; XXX, 1: 65-71

DOI: $10.5114 /$ pdia.2013.33383

\begin{abstract}
In patients with organ transplantation as compared to the general population the risk of cancer is significantly increased. The most common changes are malignant tumors of the skin, constituting 30-65\% of malignant tumors found in recipients. Potential risk factors for skin cancer after a transplant operation are: solar radiation, immunosuppressive therapy, genetic factors, infection with HPV and skin cancer transmission before transplantation. In contrast to the immunocompetent population, skin cancers in transplant recipients are dominated by squamous cell carcinoma, followed by basal cell carcinoma. Squamous cell carcinoma in patients after transplantation is characterized by a strong tendency to give local recurrences and distant metastases. Due to the high risk of developing skin cancer in transplant recipients, preventive oncology plays an important role in the long-term care of patients after transplantation. This includes: sun protection, education, and early treatment of patients with precancerous lesions. It is also stressed that systematic dermatologic studies need to be carried out in patients after transplantation surgery. The paper contains basic information about skin cancers in organ transplant recipients: epidemiology, potential risk factors, treatment and prognosis. The paper presents also a case of patient who developed squamous cell carcinoma of the skin 3 years after renal transplantation.
\end{abstract}

Key words: skin cancers, squamous cell carcinoma, basal cell carcinoma, kidney transplantation, immunosuppression.

\section{Introduction}

Patients undergoing transplant surgery are a group with an increased risk of cancer. Cancers in transplant recipients are 3-4 times more likely than in the the general population and are one of the main causes of death in this group of patients [1]. It should also be noted that patients with organ transplants have an increased risk of certain but not all cancers. Cancers the risk of which is higher in recipients include: skin cancers, lymphomas, cancers of the urinary tract, gastrointestinal tract, larynx and bronchi $[2,3]$. However, breast and prostate cancers have similar incidence in recipients compared to general population [4].

The paper contains basic information about skin cancers in organ transplant recipients: epidemiology, potential risk factors, treatment and prognosis. The paper presents also a case of patient who developed squamous cell carcinoma of the skin 3 years after renal transplantation. 


\section{Epidemiology}

Skin cancers are the most common malignant changes in patients after organ transplantation [5]. Thirty-sixty-five percent of cancers are those found in recipients [6-9], and the type of organ transplant appears to have a significant effect on the occurrence of cancer. The risk of developing skin cancer in renal transplant recipients is higher than in the liver transplant recipients, but lower as compared to patients after heart transplantation [10-12]. Among recipients dominates squamous cell carcinoma (SCC) and basal cell carcinoma (BCC) $[13,14]$, rarely are diagnosed elanoma, Kaposi's sarcoma and Merkel's cell carcinoma $[15,16]$. In contrast to the immunocompetent population, SCC is more common in transplant recipients than BCC. The incidence ratio of squamous cell carcinoma (SCC) as compared to BCC in patients after transplantation is $3.8: 1$ and $1: 4$ in the general population [17].

The incidence of skin cancer is increasing with time after transplantation, and will vary depending on the geographical region. In Australia, 10 years after transplantation, cancer of skin was found in $45 \%$, and after 20 years - in $75 \%$ of recipients [5]. The incidence of skin cancer in European countries as compared to Australia is lower and in the Netherlands, England and Italy it is $10-15 \% 10$ years after transplantation [18-20]. In the German population, 10 years after transplantation skin cancer develops in $4.8 \%$ of recipients, after 20 years - in 8.8\% [21]. However, in Asian countries, this type of cancer practically does not exist. Webb et al. found no SCC and BCC in 14\% of patients of Asian and Afro-Caribbean patients, selected from a group of 1069 respondents. The incidence of skin cancer among other Caucasian patients was $16 \%$ at 10 years and $52 \%$ 20 years after the grafting [22]. The apparent connection between the disease and the latitude is closely related to exposure to solar radiation.

Risk factors for the development of skin cancer in organ transplant recipients: immunosuppressive drugs, solar radiation, genetic factors, history of skin cancer before transplantation, HPV infection.

Immunosuppressive therapy is undoubtedly one of the most important risk factors for cancer in organ transplant recipients. The effect of immunosuppressive therapy on tumor formation is both indirect and direct. Immunosuppression impairs organ recipient response to emerging cancer cells. In addition, immunosuppressive agents can act directly by not fully known mechanisms [15].

Currently, there are no clear data on the relationship between the treatment regimen and the risk of cancer. Numerous studies comparing two immunosuppressive regimens (first based on azathioprine (AZA), the second on cyclosporine (CSA)) reported a higher incidence of tumors in the CsA-treated group than in the group treated with AZA [23-28]. Shuttleworth et al. observed a higher incidence of skin dysplasia in recipients receiving CSA as compared to those receiving AZA [26]. Glover et al. showed a high- er risk of SCC development and early development of cancer in patients who were treated with triple therapy (CSA + AZA + Pred (prednisolone)) than in the group which used Pred + AZA [27]. Similarly, Hiesse et al. showed an earlier and significantly higher incidence of non-melanoma skin cancer (NMSC) in patients treated with CSA [25]. Published studies also show that the incidence of skin cancers in recipients treated with AZA is comparable to the frequency of cancer development in patients treated with CSA [1, 28-30].

It seems that the drug the use of which may be associated with a lower risk of developing cancer as compared to AZA is mycophenolate mofetil (MMF). Studies comparing the group treated with AZA with an MMF-treated group favored MMF [31-34]. At a conference in Washington in 2004, Ulrich and Stockfleth presented the results of prospective studies on the development of cancer in kidney and heart transplant recipients receiving triple immunosuppression (CSA + AZA + Pred/CsA + MMF + Pred/TAC (tacrolimus) + AZA + Pred/TAC + MMF + Pred) The study material included 1500 recipients. A significantly lower incidence of SCC in patients treated with TAC + MMF + Pred as compared to patients treated with TAC + AZA + Pred was observed. In the group of recipients receiving CSA $+M M F+$ Pred, a lower percentage of tumors was reported than in the group receiving CSA + AZA + Pred, although the difference was not statistically significant [31]. A lower incidence of cancer in patients treated with MMF as compared to AZA-treated patients confirmed the data from two registers: OPTN/UNOS (Organ Procurement and Transplant Network/United Network for Organ Sparing) and CTS (Collaborative Transplant Study) [31, 32]. The results in cited reports suggest higher oncological safety in renal transplant patients receiving MMF. Therefore, in transplant recipients at high risk of developing skin cancer AZA is often replaced by MMF [31].

In the case of TAC, a relatively low but increasing incidence of cancer was shown. The analysis of the OPTN/UNOS, which evaluated more than 62 thousand kidney transplants performed in 1998-2003, showed a smaller percentage of skin cancers and solid tumors in patients treated with TAC as compared to those treated with CSA [33]. Cowlrick et al. analyzed five prospective multicenter studies with TAC as the primary immunosuppressant. Among 2435 recipients treated with regimens: TAC + GS + AZA or TAC + MMF + GS, after a year of observation, cancer developed in $1.63 \%$, after 2 years in $2.55 \%$ and after 3 years in $3.4 \%$ of transplant recipients. Skin cancers accounted for $37.3 \%$ of all cancers [35].

Although so far it has been failed to clearly prioritize individual drugs according to their impact on the development of skin cancer, most authors agree on one thing, namely occurrence of cancer in transplant recipients is affected by the exposure time and the level of immunosuppression [15, 23, 36]. Patients receiving immunosuppressive drugs for a period of 5 years or longer [37] as well as the heart recipients, who have a higher level of 
immunosuppression $[15,23]$ are more likely to suffer from skin cancer.

Ultraviolet radiation is one of the better-known factors that cause the development of skin cancer in both the immunocompetent population and in organ transplant recipients [38, 39].

So far, many conflicting results have been published in studies evaluating the association of HLA risk of developing skin cancer in transplant recipients. A few works have shown a greater incidence of SCC among the recipients with such antigens as HLA-A11, -B27, -DR7 [37, 40, 41], by homozygote DR and in the case of incompatibility of antigens HLA-B between the donor and the recipient [40]. Other authors did not observe such a relationship [23, 42, 43]. One report suggests the protective effect of HLA-A11 antigen on the development of SCC [44]. More and more authors are inclined to take a position that there is no relationship between HLA antigens and the development of skin cancer after transplantation [23, 42].

Genetic factors beyond the influence of HLA include the influence of antioxidant enzyme activity of GST (Glutathione-s-transferase). This enzyme inhibits the effects of free radicals, which are formed after exposure to UV radiation. This suggests the influence of polymorphisms of genes GSTM1, GSTT1 and GSTP1 on the development of SCC in patients after renal transplantation. The study conducted by Ramsay et al. has shown a correlation between the GSTM1 gene and an increased risk of SCC, especially in patients exposed to sunlight $[45,46]$.

Danpanich and Kasiske observed a twofold increase in the risk of developing skin cancer in transplant recipients with a history of skin cancer [47]. According to the Clinical Transplant Tumor Registry, skin cancer (NMSC or melanoma) developed in $62 \%$ of patients after a transplant, who had been treated for cancer of the skin in the past [48]

\section{Prevention and treatment}

An important issue in the care of chronic patients after organ transplantation is the selection of recipients at high risk of developing cancer and preventive oncology. Ways to reduce the risk of developing skin cancer in transplant recipients include:

- avoid exposure to UV radiation and use sun protection $[5,14,49]$,

- treatment of precancerous lesions [5, 49],

- treatment of HPV infection [50].

In theory, reduction of exposure to UV radiation seems to be the simplest way. Organ recipients need to be educated about the need to use sunscreens and have periodic self-control. It turns out, however, that it is often an insufficient procedure practiced by patients. Studies have shown that only $40 \%$ of recipients follow sunscreen recommendations, and $90 \%$ use protective sunblocks with too low SPF [51].

Treatment of skin cancers in organ transplant recipients consists of two basic strategies: to restore the effi- ciency of the immune system and to remove the tumor. The first of these objectives can be achieved by reduction in immunosuppression. The second objective is achieved by means of surgery, and sometimes radiotherapy. Dose reduction of immunosuppressive drugs is used in cases of SCC with a high risk of local recurrence or metastases (multiple tumors, low-differentiated, tumor size $>2 \mathrm{~cm}$, the depth of infiltration of 3-4 mm, location on the forehead, ears, lips). Patients with SCC without high-risk factors may require surgery only [15].

\section{Case report}

A 54-year-old patient with end-stage renal disease in the course of diabetic nephropathy. Type 1 diabetes was diagnosed at the age of 28 years while she was treated in the Department of Internal Medicine in Zgierz (1983) due to urinary tract infections and dermatitis due to vitamin $B$ complex administration. The treatment with ultralente and semilente insulin was introduced. In 1998, she was treated with radioiodine because of goiter. In December 2000, she was hospitalized in the Dialysis Center in Zgierz because of a severe heart failure in the form of lower leg edema. She had symptoms of kidney failure (increased urea and creatinine values). In an anamnesis, beside the complications of diabetes: nephropathy and hallux amputation of the right (diabetic) foot, high blood pressure was noted. She was treated by peritoneal dialysis renal replacement therapy from July 2002 to December 2003. On 31 December 2003 in the Department of Urology and Transplantation, allogeneic renal transplantation was performed. Immunosuppression regimen of prednisone + cyclosporine + azathioprin was used.

In 2005, she was treated in the Department of General Surgery in Zgierz due to an ulcer of the right hand back. The histopathological diagnosis was: ulceratio et granulatio. In February 2006, she was treated again because of the right hand ulcer, this time in histopathology: SCC invasivum G2, excisio incompleta. In April 2006, in the Department of Surgery and Oncological Gynecology, Medical University in Lodz, a radical excision was performed, and the defect was covered with a skin graft. In February 2009, there was a recurrence of skin cancer. In the Department of Plastic Surgery, Medical University in Lodz, a lump in the angle of the left eye was excised (Figure 1). Histological examination confirmed the suspicion of recurrence: carcinoma planoepitheliale praeinvasivum (Figure 2), but unfortunately there was no radical surgery, so in April the scar was widely excised and no cancer cells were found in histopathology, but features of keratosis senilis (keratosis senilis typus atrophicus) were observed (Figure 3). In December 2009, a small ulcer appeared at the skin graft on the back of the right hand, excision was performed and evaluated histopathologically: ca planoepitheliale intraepidermale (morbus Boweni) and elastosis cutis (Figure 4) was found. In March 2010, she was treated due to tumor of the nose 

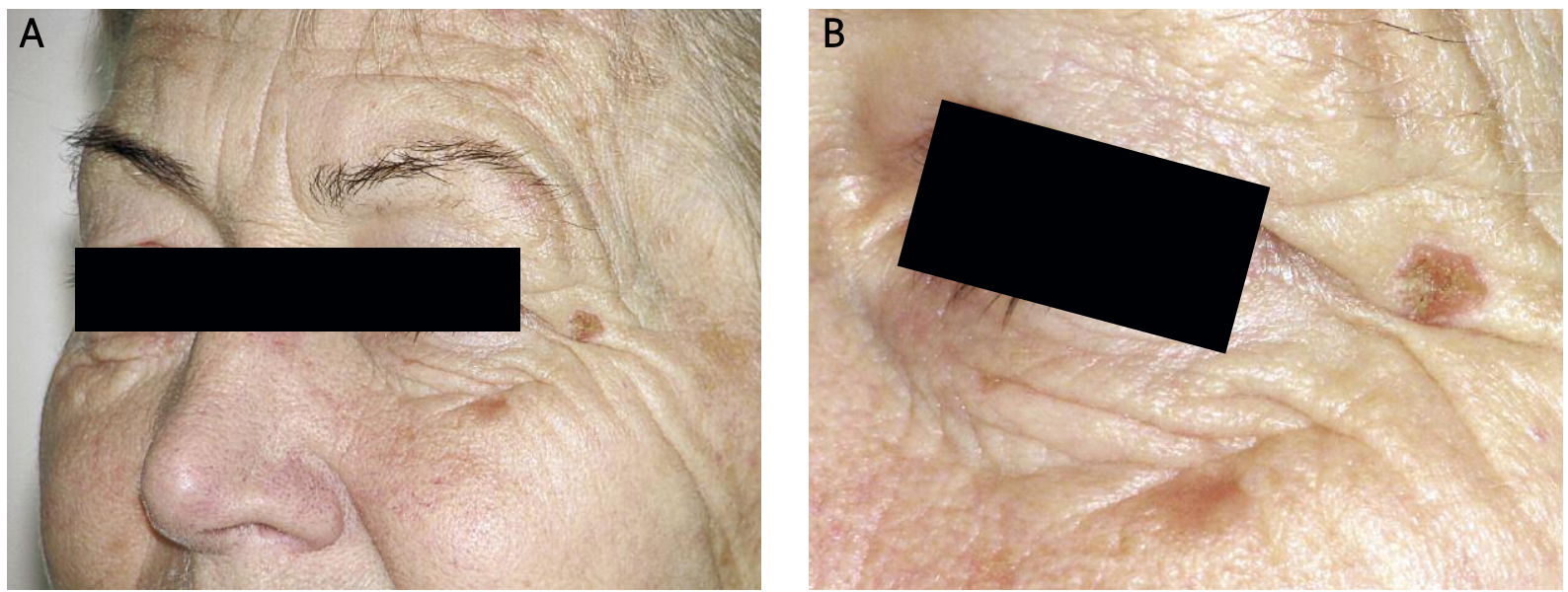

Figure 1 A, B. Women 59 years old. Dg.: Tumor of the left angle of the eye

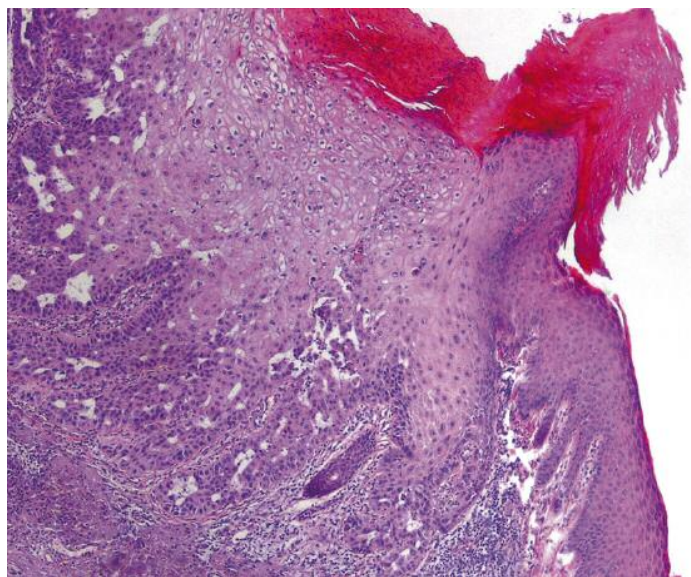

Figure 2. Ca planoepitheliale praeinvasivum. Staining: $\mathrm{H}+\mathrm{E}$, magnification $120 \times$

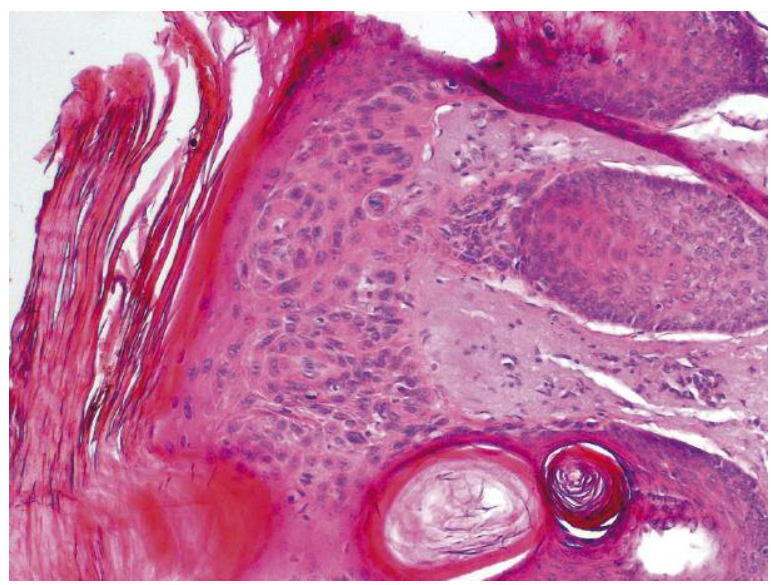

Figure 4. Bowen's disease. Staining: $\mathrm{H}+\mathrm{E}$, magnification $320 x$

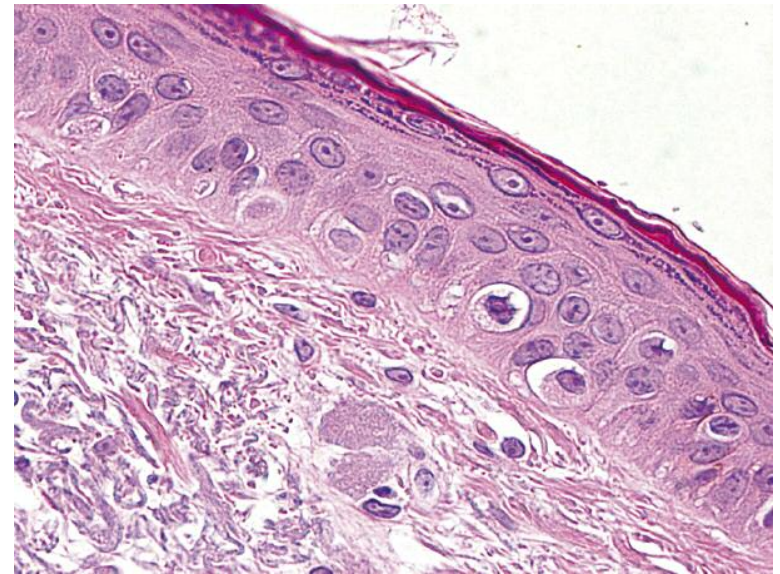

Figure 3. "Senile" keratosis: atrophic type of elastosis in the dermis. Staining: $\mathrm{H}+\mathrm{E}$, magnification $500 \times$

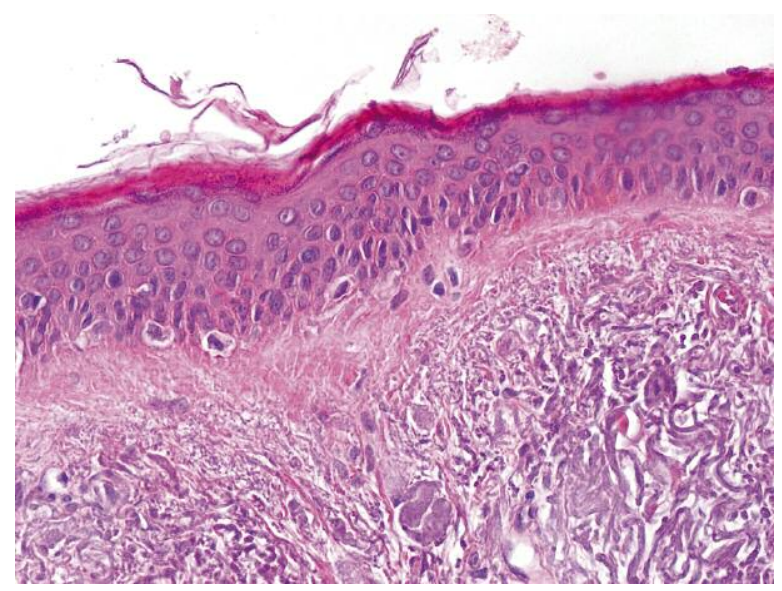

Figure 5. Acanthocytic epidermal hyperplasia with severe dysplasia and hyperkeratosis. Staining: $\mathrm{H}+\mathrm{E}$, magnification 200x 
with the following diagnosis: hyperplasia epithelii planners cum dysplasia gravis atque hyperkeratosi (Figure 5).

\section{Discussion}

This case is an illustration of an increased risk of cancer recurrence in organ recipients. In approximately 50\% of patients after transplantation, SCC develops change as the plural $[2,52]$ with an aggressive course and tendency to frequent recurrence and metastasis $[2,53,54]$. The study, which covered 2075 Dutch recipients showed the development of skin cancer in $53 \%$ of patients. In $48 \%$ of patients after treatment another cancer of the same or different type of pathology developed. During followup 2 patients died: 1 due to SCC and 1 patient due to Merkel cells carcinoma metastases to the lung [55]. Aggressive cancerous disease was also reported by Australian researchers. Veness et al. reported that skin cancer developed in $41 \%$ of the observed recipients, half of these patients died [56]. According to another Australian study, skin cancer was the cause of death of $27 \%$ of recipients. Follow-up was 4 years [57]. However, Californian authors observed aggressive cancerous disease in $13 \%$ of patients after transplantation [58].

In the context of the presented patient it seems very important to screen for skin cancer in organ transplant recipients. In these patients, physical examination of the skin should be performed every 12 months [5, 15]. According to Otley and Berg, in cases where there are no other known risk factors for cancer except immunosuppression, the search for cancer and premalignant skin changes should be a part of the routine performed by the patient. Only patients with a high risk of developing skin cancer after transplantation should be referred to a dermatologist [15]. However, Dreno takes a position that dermatological care should be offered to all recipients of organs [5]. Monthly selfcontrol in transplant patients is also recommended.

Secondary prevention for recipients should include regular visits to the dermatologist every 6 months. According to the US recommendations, this interval should be shorter in the case of multiple tumors (2-4 months), a high risk of relapse (3 months), melanoma (2-3 months) and the presence of metastases (2 months) [15]. In recipients of multiple organs and/or recurrent skin cancer, prevention can be effective using systemic retinoid therapy, such as isotretin and recently acitretin $[59,60]$. A randomized study performed on a small group of recipients showed a significant decrease in the number of new cases of SCC in patients treated with acitretin. During a 6-month followup, SCC developed in 2 patients treated with acitretin and in 18 in the placebo group [61]. Mc Kenna and Murphy confirmed a significant reduction in new cases of skin cancer after using acitretin. During a 5-year follow-up, the authors reported no serious side effects of this drug therapy [60]. Last but not least, remember that because of the numerous side effects of acitretin, such as liver failure or hyperlipidemia, observation of patients during therapy is required $[59,62]$.

\section{Conclusions}

Transplant patients incur a higher risk of developing skin cancer as compared to the general population. Therefore, in the case of organ transplant, recipients should apply increased oncological vigilance. In recipients treated for skin cancer, recurrence of the disease is often observed. Therefore, it is very important to have regular dermatological control, enabling early diagnosis and effective therapy, thus to prevent a potential cancer recurrence.

\section{References}

1. Sheil AG. Development of malignancy following renal transplantation in Australia and New Zealand. Transplant Proc 1992; 24: $1275-9$.

2. Penn I. Post-transplant malignancy: the role of immunosuppression. Drug Saf 2000; 23: 101-13.

3. Penn I. Cancers in renal transplant recipients. Adv Ren Replace Ther 2000; 7: 147-56.

4. Penn I, Brunson ME. Cancers after cyclosporine therapy. Transplant Proc 1988; 20 (Suppl 3): 885-92.

5. Dreno B. Skin cancers after transplantation. Nephrol Dial Transplant 2003; 18: 1052-8.

6. Penn I. Post-transplant malignancies. Transplant Proc 1999; 31: $1260-2$.

7. Birkeland SA, Storm HH, Lamm LU, et al. Cancer risk after renal transplantation in the Nordic countries, 1964-1986. Int J Cancer 1995; 60: 183-9.

8. Gruber SA, Gillingham K, Sothern RB, et al. De novo cancer in cyclosporine-treated adult primary renal allograft recipients. Clin Transplant 1994; 8: 388-95.

9. Machnicki G, Lentine KL, Salvalaggio PR, et al. Kidney transplant Medicare payments and length of stay: associations with comorbidities and organ quality. Arch Med Sci 2011; 7: 278-86.

10. Jansen P, Hansen S, Moller B, et al. Skin cancer in kidney and heart transplant recipients and different long-term immunosuppressive therapy regimens. I Am Acad Dermatol 1999; 40: 177-86.

11. Gjersvik P, Hansen S, Moller B, et al. Are heart transplant recipients more likely to develop skin cancer than kidney transplant recipients? Transplant Int 2000; 13 (Suppl 1): 380-1.

12. Penn I. Posttransplantation de novo tumors in liver allograft recipients. Liver Transpl Surg 1996; 2: 52-9.

13. Wyrzykowska N, Rosińska-Więckowicz A, Bartoszak L, et al. Bowen's disease and basal cell carcinoma in a renal transplant recipient - case report. Postep Derm Alergol 2011; 28: 138-141.

14. Witmanowski H, Lewandowicz E, Sobieszek D, et al. Facial skin cancers: general information and an overview of treatment methods. Postep Derm Alergol 2012; 29: 240-55.

15. Berg D, Otley CC. Skin cancer in organ transplant recipients: epidemiology, pathogenesis, and management. J Am Acad Dermatol 2002; 47: 1-17.

16. Douds AC, Mellotte GJ, Morgan SH. Fatal Merkel-cell tumour (cutaneous neuroendocrine carcinoma) complicating renat transplantation. Nephrol Dial Transplant 1995; 10: 1717-21.

17. Ramsay HM, Fryer AA, Reece S, et al. Clinical risk factors associated with nonmelanoma skin cancer in renal transplant recipients. Am J Kidney Dis 2000; 36: 167. 
18. Hartevelt MM, Bavinck JN, Kootte AM, et al. Incidence of skin cancer after renal transplantation in the Netherlands. Transplantation 1990; 49: 506-9.

19. Naldi L, Fortina AB, Lovati S, et al. Risk of nonmelanoma skin cancer in Italian organ transplant recipients. A registrybased study. Transplantation 2000; 70: 1479-84.

20. London NJ, Farmery SM, Will EJ, et al. Risk of neoplasia in renal transplant patients. Lancet 1995: 346: 403-6.

21. Behrend M, Kolditz M, Kliem V, et al. Malignancies in patients under long-term immunosuppression after kidney transplantation. Transplant Proc 1997; 29: 834-5.

22. Webb MC, Comptom F, Andrews PA, Koffman CG. Skin tumours posttransplantation: a retrospective analysis of 28 year's experience at a single centre. Transplant Proc 1997; 29: 828-30.

23. Jensen $P$, Hansen S, Moller B, et al. Skin cancer in kidney and heart transplant recipients and different long-term immunosuppressive therapy regiment. J Am Acad Dermatol 1999; 40: 177-86.

24. Schmidt R, Stippel D, Schmitz-Rixen T, Pollok M. Tumors after renal transplantation. Urol Int 1996; 57: 21-6.

25. Hiesse C, Larue JR, Kriaa F, et al. Incidence and type of malignancies occurring after renal transplantation in conventionally and in cyclospone-treated recipients: single-center analysis of a 20-year period in 1600 patients. Transplant Proc 1995; 27: $2450-1$.

26. Shuttleworth D, Marks R, Griffin PJ, Salaman JR. Epidermal dysplasia and cyclosporine therapy in renal transplant patients: a comparison with azathioprine. Br J Dermatol 1989; 120: 551-4.

27. Glover MT, Deeks JJ, Raftery MJ, et al. Immunosuppression and risk of non-melanoma skin cancer in renal transplant recipients. Lancet 1997; 34: 398

28. Bouwes Bavinck JM, Hardie DR, Green A, et al. The risk of skin cancer in renal transplant recipients in Queensland, Australia: a follow-up study. Transplantation 1996; 61: 715-21.

29. Fortina AB, Caforio AL, Piaserico S, et al. Skin cancer in heart transplant recipients: frequency and risk factor analysis. J Heart Lung Transplant 2000; 19: 249-55.

30. Gruber SA, Gillingham K, Sothern RB, et al. De novo cancer in cyclosporine-treated and non-cyclosporine-treated adult primary. Clin Transplant 1994; 8: 388-95.

31. Ulrich C, Stockfleth E. Azathioprine, UV light, and skin cancer in organ transplant patients - do we have an answer? Nephrol Dial Transplant 2007; 22: 1027-9.

32. Buell JF, Gross TG, Woodle ES. Malignancy after transplantation. Transplantation 2005; 80: (Suppl 2): 254-64.

33. Kauffman HM, Cherikh WS, McBride MA, et al. Post-transplant de novo malignancies in renal transplant recipients: the past and present. Transplant Int 2006; 19: 607-20.

34. Robson G, Cecka JM, Opelz G, et al. Prospective registry-based observational cohort study of the long-term risk of malignancies in renal transplant patients treated with mycophenolate mofetil. Am J Transplant 2005; 5: 2954-60.

35. Cowlrick I, Delventhal H, Kaipainen K, et al. Three-year followup of malignancies in tacrolimus-treated renal recipients - an analysis of European multicentre studies. Clin Transplant 2008; 22: 372-7.

36. Zamanian A, Farshchian M. Neoplastic skin lesions in Iranian renal transplant recipients: the role of immunosuppressive therapy. J Drugs Dermatol 2007; 6: 703-6.

37. Czarnecki D, Watkins F, Leahy S, et al. Skin cancers and HLA frequencies in renal transplant recipients. Dermatology 1992; 185: 9-11.
38. Jenerowicz D, Silny W, Dańczak-Pazdrowska A, et al. Environmental factors and allergic diseases. Ann Agric Environ Med 2012; 19: 475-81.

39. Śpiewak R. The substantial differences between photoallergic and phototoxic reactions. Ann Agric Environ Med 2012; 19: 888-9.

40. Bouves Bavinck JN, Vermeer BJ, Van der Woude J, et al. Relation between skin cancer and HLA antigens in renal-transplant recipients. N Engl J Med 1991; 325: 843-8.

41. Bavinck JNB, Class FHJ, Hardie DR, et al. Relation between HLA antigens and skin cancer in renal transplant recipients in Queensland, Australia. J Invest Dermatol 1997; 108: 708-11.

42. Dyall-Smith D, Ross JB. Cutaneous malignancies in renal transplant recipients from Nova. Scotia, Canada. Aust J Dermatol 1995; 36: 79-82.

43. Glover MT, Bodmer J, Bodmer W, et al. HLA antigen frequencies in renal transplant recipients and non-immunosuppressed patients with non-melanoma skin cancer. Eur J Cancer 1993; 29A: 520-4.

44. Bavinck JNB, Kootte AMM, Van der Woude FJ, et al. On a possible protective effect of HLA-A11 against skin cancer and keratotic skin lesions in renal transplant recipients. J Invest Dermatol 1991; 97: 269-72.

45. Ramsay HM, Harden PN, Reece S, et al. Polymorphisms in glutathione S-transferases are associated with altered risk of nonmelonoma skin cancer in renal transplant recipients: a preliminary analysis. J Invest Dermatol 2001; 117: 251-5.

46. Osmola-Mańkowska A, Silny W, Dańczak-Pazdrowska A, et al. The sun - our friend or foe? Ann Agric Environ Med 2012; 19: 805-9.

47. Danpanich E, Kasiske BL. Risk factors for cancer in renal transplant recipients. Transplantation 1999; 68: 1859-64.

48. Penn I. Malignant melanoma in organ allograft recipients. Transplantation 1996; 61: 274-8.

49. Rubel JR, Milford EL, Abdi R. Cutaneous neoplasms in renal transplant recipients. Eur J Dermatol 2002; 12: 532-5.

50. Hardwood CA, Surentheran T, McGregor JM, et al. Human papilloma virus infection and non-melanoma skin cancer in immunosuppressed and immunocompetent individuals. J Med Virol 2000; 61: 289-97.

51. Butt A, Roberts DL. Renal transplant recipients and protection from sun: need for education. Lancet 1997; 349: 179-80.

52. Ramsay HM, Fryer AA, Hawley CM, et al. Epidemiology and Health Services Research, Nonmelanoma skin cancer risk in the Queensland renal transplant population. Br J Dermatol 2002; 147: 950-6.

53. Euvrard S, Kanitakis J, Pouteil-Noble C, et al. Aggressive squamous cell carcinomas in organ transplant recipients. Transplant Proc 1995; 27 : 1767-8.

54. Adamson R, Obispo E, Dychter S, et al. High incidence and clinical course of aggressive skin cancer in heart transplants: a single-center study. Transplant Proc 1998; 30: 1124-6.

55. Winkelhorst JT, Brokelman WJ, Tiggeler RG, et al. Incidence and clinical course of de-novo malignancies in renal allograft recipients. Eur J Surg Oncol 2001; 27: 409-13.

56. Veness MJ, Quinn DI, Ong CS, et al. Aggressive cutaneous malignancies following cardiothoracic transplantation: the Australian experience. Cancer 1999; 85: 1758-64.

57. Ong CS, Keogh AM, Kossard S, et al. Skin cancer in Australian heart transplant recipients. J Am Acad Dermatol 1999; 40: 27-34.

58. Pollard JD, Hanasono MM, Mikulec AA, et al. Head and neck cancer in cardiothoracic transplant recipients. Laryngoscope 2000; 110: 1257-61. 
59. Di Giovanna JJ. Posttransplantation skin cancer: scope of the problem, management, and role for systemic retinoid chemoprevention. Transplant Proc 1998; 30: 2771-5.

60. McKenna DB, Murphy GM. Skin cancer chemoprophylaxis in renal transplant recipients: 5 years of experience using lowdose acitretin. Br J Dermatol 1999; 140: 656-60.

61. Bavinck JN, Tieben LM, Van der Woude FJ, et al. Prevention of skin cancer and reduction of keratotic skin lesions during acitretin therapy in renal transplant recipients: a double-blind, placebo-controlled study. J Clin Oncol 1995; 13: 1933-8.

62. Di Giovanna JJ. Retinoid chemoprevention in high-risk skin cancer patients. J Am Acad Dermatology 1998; 39 (Suppl 1): 82-5. 